\title{
PENGEMBANGAN DESAIN UKIR KAYU PADA INDUSTRI FURNITURE DI JEPARA
}

\author{
Eddy Supriyatna1; Agustinus Purna Irawan2; Maitri Widya Mutiara3 \\ ${ }^{1}$ Program Studi Desain Interior, Universitas Tarumanagara, Jakarta \\ Email:eddysmarizar@yahoo.com \\ 2 Program Studi Teknik Mesin, Universitas Tarumanagara, Jakarta \\ Email:agustinus@untar.ac.id \\ 3 Program Studi Desain Interior, Universitas Tarumanagara, Jakarta \\ Email: maitrim@fsrd.untar.ac.id
}

\begin{abstract}
ABSTRAK
Industri furnitur di Jepara sedang mengalami proses perubahan dalam mengatisipasi pasar ekspor. Desain-desain fuirniture yang diproduksi cenderung mengikuti keinginan dan kebutuhan pasar global yang nyaris tidak menampilkan ukiran kayu dalam desain furniturenya. Padahal, ukir kayu Jepara merupakan keunggulan Jepara yang telah berkembangn secara turun-temurun, beratus tahun lamanya. Tampaknya potensi ukir kayu tersebut tidak diberdayakan sebagai alat daya saing ekspor. Oleh sebab itu, diperlukan pengembangan desain furniture ukir kayu yang disesuaikan dengan tuntutan keinginan dan kebutuhan konsumennya di pasar ekspor. Di dalam konteks penelitian ini, pengembangan desain dilakukan setelah melakukan identifikasi pasar ekspor di pasar global dan mengidentifikasi potensi produksi yang dimiliki oleh kalangan industri Jepara. Identifikasi pasar menghasilkan karakteristik desain furnitur yang sesuai dengan tuntutan ekspor, adapun identifikasi potensi produksi sebagai pertimbangan di dalam pengembangan desain. Luaran yang dicapai adalah desain furniture ukir kayu, prototype furniture knockdown dan beragam jenis desain ukiran, baik diproses manual maupun masinal. Penelitian kualitatif ini menggunakan pendekatan multidisiplin bidang desain, teknologi, dan manajemen pemasaran.
\end{abstract}

Kata Kunci: Desain furniture, ukir kayu, pasar ekspor, pengembangan

\begin{abstract}
The furniture industry in Jepara is undergoing a process of change in anticipating the export market. Furniture designs produced tend to follow the desires and needs of the global market which barely displays wood carvings in their furniture designs. In fact, Jepara wood carving is an advantage of Jepara which has been developed for generations, hundreds of years. It seems that the potential for carving wood is not empowered as a means of export competitiveness. Therefore, it is necessary to develop wooden carved furniture designs that are tailored to the demands and desires of consumers in the export market. In the context of this research, design development is carried out after identifying the export market in the global market and identifying the production potential of the Jepara industry. Market identification produces furniture design characteristics that are in line with export demands, while the identification of production potential as a consideration in design development. The achieved output is wood carved furniture design, prototype knockdown furniture and various types of carving designs, both processed manually and masinal. This qualitative research uses a multidisciplinary approach in the fields of design, technology, and marketing management.
\end{abstract}

Keywords: Furniture design, wood carving, export market, development

\section{PENDAHULUAN} Latar Belakang

Fenomena yang berkembang di Jepara saat ini adalah desain furniture yang diproduksi cenderung mengikuti pesanan dari konsumen asing (buyers). Identitas Jepara sebagai kota Ukir, ada kecenderungan tidak tampak dalam perkembangan industri furniture. Padahal, Jepara merupakan "raja" ukir kayu yang sudah dikenal dimancanegara. Bahkan Gustami, pakar furniture Jepara mengatakan Jepara sudah dikenal sebagai pusat industri furniture ukir kayu sejak ratusan tahun lalu. Gustami menguraikan bahwa, 
kehadiran furniture ukir kayu di Jepara telah dimulai sejak Masa Hindu, Islam, Kolonial, sampai Masa Kemerdekaan dan Pembangunan, bahkan pengaruhnya masih dirasakan sampai saat ini.

Sehubungan dengan desain interior, furniture merupakan sarana interior yang sangat penting untuk mendukung aktivitas manusia di dalam ruangan. Oleh sebab itu, furniture selalu didesain sesuai harapan para penggunanya, walaupun tidak lagi menggunakan ukiran sebagai ornamen unggulannya.

Sejak lama, kegiatan ekspor furniture ukir kayu telah menjadi andalan utama bagi masyarakat Jepara, sehingga mereka berhubungan langsung dengan konsumen dari luar negeri, termasuk pasokan desain produknya.

Hal itu juga terungkap dalam seminar yang disampaikan oleh Supriyatna-Marizar di Jepara pada tanggal 21 Juni 2005 (Kar-59., Suara Merdeka, 22 Juni 2005), jika kita mengamati fenomena desain furniturel yang berkembang di Jepara, ada kecenderungan bahwa, desain-desain mebel yang diproduksi pada umumnya berdasarkan pesanan dari konsumen. Desain-desain furniture yang diproduksi berorientasi pada keinginan-keinginan konsumen, dan selalu dipengaruhi oleh konsumennya. Apapun karakteristik desain yang diberikan oleh konsumen akan diterima dan dikerjakan untuk segera dijadikan produk, dijual dan cepat mendapatkan uang. Desain dipaksakan untuk diproduksi, karena ingin cepat mendapatkan keuntungan. Lebih lanjut, Marizar mengungkapkan bahwa, adakalanya pemesan memaksakan kehendak atau mendikte desainer mebel. Celakanya, desainer selalu mengabulkan permintaan konsumen karena ingin cepat dapat order, sehingga peran desainer menjadi identik dengan tukang gambar (Sup, Kompas, 25 Juni 2005). Prinsipnya, desain yang berkembang di Jepara kebanyakan menyesuaikan dengan pesanan para pembelinya (Grs., Radar Kudus, 24 Juni 2005).

Di dalam konteks ini, dapat dikatakan bahwa desain furniture ukir kayu Jepara diproduksi hanya untuk kepentingan komersial semata, tanpa memikirkan nilai tambah dari keunggulan lokal (local genius) yang akan menjadi keunggulan kompetitif. Oleh sebab itu dapat diduga bahwa karakteristik desain furniture di Jepara muncul karena pengaruh faktor-faktor luar (eksternal) yang kompromi terhadap pembeli asing dalam upaya memperluas perdagangan luar negeri melalui ekspor, bahkan para pembeli tersebut menjadi pengendali bagi kehadiran desain mebel di Jepara. Kekuatan-kekuatan di luar kekuatan desain itu sendiri yang telah merekonstruksi elemen-elemen visual dalam desain furniture di Jepara, sehingga desain tidak menjadi fokus dalam pengembangan, karena faktor utama yang dikembangkan adalah faktor ekonomi dan politik di wilayah Jepara.

Pada masa lampau, Jepara dikenal sebagai kota penting di tanah Jawa. Sejak pemerintahan ratu Shima pada tahun 674 Masehi, Jepara sudah dikunjungi kapal asing, baik yang datang dari Asia maupun Eropa. Oleh sebab itu, Jepara menjadi pintu gerbang masuknya pengaruh asing, terutama negara-negara Eropa (Gustami, 2000, p. 1). Pada abad ke-16, artivitas perdagangan mulai berkembang di Nusantara, mulai dari kehadiran Portugis, Belanda, Spanyol, dan Inggris (Gustami, 2000, p.13). Belanda bersama perusahaan dagangnya (VOC) juga mendatangkan tukang-tukang dari negeri asalnya, sehingga telah membawa pengaruh unsur-unsur seni ke dalam seni budaya Indonesia (Gustami, 2000, p. 14). Lebih lanjut Gustami mengungkapkan bahwa, produk mebel ukir di Jepara berkembang lebih pesat sesudah masuknya pengaruh Eropa mulai abad ke 16 sampai abad ke 18 itu (Gustami, 2000, p. 200).

Menurut Gustami (2000) dalam buku "Seni Kerajinan Mebel Ukir Jepara: Kajian Estetik melalui Pendekatan Multidisiplin," disebutkan bahwa pada abad ke-16 sampai abad ke-18, produk furniture ukir di Jepara berkembang lebih pesat sesudah masuknya pengaruh Eropa, bahkan sampai memasuki abad ke20 (Gustami, 2000, p. 200-201). Demikian pula dalam buku "Mebel Klasik: Paradigma Desain di Eropa" yang disusun oleh Eddy Supriyatna-Marizar (2003) dijelaskan bahwa, kehadiran desain furniture klasik di Eropa merupakan representasi dari kekuatan ambisi-ambisi manusia untuk melegitimasi status sosialnya. Sebab, furniture dapat dijadikan sarana untuk menghadirkan citra para pemakainya, sekaligus sebagai citra dari budaya yang berkembang di tengah dinamika masyarakatnya (Gustami, 2000, p. 1). Lebih lanjut Supriyatna-Marizar mengatakan bahwa, ketika bangsa Eropa masih menjajah Indonesia selama ratusan tahun memberikan dampak yang mengalir deras masuk ke dalam tatanan budaya Indonesia. Jika kita amati, peninggalan bangsa Eropa tersebut masih tercermin pada karya-karya desain furniture di Jepara. 
Gaya furniture buatan Jepara memiliki karakteristik yang sama dengan gaya furniture klasik Eropa, seperti Chippendale, Sheraton, Queen Anne, Empire, dan masih banyak lagi (Gustami, 2000, p. 2). Furniture Eropa dengan berbagai karakter gayanya itu dapat dipelajari dari buku An Encyclopedia of Chairs karya Simon Yates (1988). Dalam buku tersebut diuraikan beragam gaya Furniture Eropa mulai dari sebelum tahun 1600 sampai karya desain furniture tahun 1988. Gaya furniture klasik tersebut yang diduga berpengaruh besar terhadap desain furniture di Jepara.

Para pengusaha di Jepara masih banyak yang meremehkan aspek desain sebagai elemen penunjang kompetisi pasar. Orang masih suka meniru desain-desain yang sudah populer di masyarakat, sehingga perolehan nilai tambah menjadi rendah (Supriyatna-Marizar, April-Mei 1999, p. 57). Kondisi itu sudah berlangsung lama, sejak furniture ukir Jepara muncul sebagai kekuatan ekonomi masyarakatnya. Apalagi tokoh-tokoh yang memunculkan desain furniture ukir Jepara adalah wanita, jadi cenderung home industry. Hal itu sudah terjadi ratusan tahun lalu sejak Ratu Kalinyamat, Ratu Shima, R.A. Kartini sampai Ibu Tien Soeharto (Gustami, 1997, p. 336-349; juga pada Gustami, 2000, p. 80-121). Esensinya, bahwa produk ukir kayu merupakan potensi terbesar di Jepara, terutama yang diterapkan di dalam furniture sebagai ornamen.

Tampaknya saat ini, potensi desain ukir kayu di Jepara itu tidak banyak diberdayakan sebagai daya saing ekspor, sehingga pertumbuhan industri furniture Jepara ada kencenderungan stagnan, bahkan menurun. Hal itu diperkuat pendapat Daniel H. Pink yang telah menempatkan desain di urutan pertama dalam kecerdasan manusia sebagai high concept dan high touch (Pink, 2007: 71). Di dalam konteks ini, pengembangan desain dirumuskan secara universal (Oliver, 2008), agar sesuai dengan karakteristik desain global. Dengan demikian sentuhan konsep pengembangan desain menjadi salah satu solusi untuk meningkatkan daya saing ekspor yang sesuai potensi Jepara dan relevan dengan tuntutan pasar eskpor ke China dan Jepang secara uiversal.

\section{Rumusan Masalah}

Bagaimana mengembangkan desain ukir kayu untuk industri furniture di Jepara yang sesuai dengan potensi pasar ekspor dan potensi produksi?

\section{METODE PENELITIAN}

Penelitian kualitatif ini menggunakan pendekatan multidisiplin bidang desain, teknologi, dan manajemen pemasaran. Desain dikembangkan berdasarkan hasil riset pasar ekspor, khususnya China dan Jepang. Disiplin manajemen pemasaran ekspor menjadi landasarn di dalam menganalisisnya. Desain furniture dibuat dengan pendekatan teknologi produksi sebagai dasar di dalam mendesain.

Adapun tujuan penelitian adalah melakukan pengembangan desain furniture ukir kayu yang sesuai pasar global (ekspor) dengan menampilkan nilai daya saing berupa nilai-nilai lokal Jepara, berupa ukiran kayu yang dipadu dengan nilai global, seperti knockdown system dan stilasi ornamen Jepang atau China. Urgensi penelitian ini adalah untuk memberikan masukan bagi pengembangan industri furniture di Jepara, berupa desain dan prototype yang berorientasi ekspor.

\section{HASIL DAN PEMBAHASAN}

Berdasarkan hasil observasi, ditemukan berbagai potensi produksi yang belum diberdayakan secara optimal. Sarana mesin produksi untuk mempercepat produksi dan meningkatkan kapasitas produksi belum banyak diberdayakan. Produksi dilakukan dengan cara konvensional dan manual. Keterampilan mengukir pun cenderung kurang diberdayakan dan kurang diapresiasi, sehingga melahirkan desain-desain furniture yang tidak menggunakan hiasan ukir kayu. Desain yang bergaya minimalis dan modern tanpa hiasan menjadi trend produksi yang fenomenal sampai saat ini, karena mudah dan cepat untuk diproduksi, apalagi menggunakan mesin produksi. Sementara, para pengukir beralih ke pekerjaan lain yang tidak ada hubungannya dengan ukiran.

Tampaknya, potensi besar yang dimiliki Jepara tidak banyak diberdayakan sebagai daya saing ekspor, sehingga pertumbuhan industri furniture Jepara ada kencenderungan stagnan, bahkan menurun. Apalagi 
aspek desain belum dijadikan alat yang dapat menciptakan nilai tambah ekonomi. Salah satu upaya untuk meningkatkan daya saing dapat dilakukan melalui pengembangan desain furniture yang sesuai dengan budaya dan tradisi yang tumbuh di tengah masyarakatnya. Pengembangan dan penciptaan desain sangat diperlukan ketika persaingan pasar semakin ketat. Nyaris di seluruh negara di dunia telah menempatkan desain sebagai kekuatan pasar agar mampu berkompetisi.

Berdasarkan hasil analisis yang diolah dari FGD, observasi, dan kajian teoretik, maka strategi pengembangan desain ukir kayu pada furniture di Jepara diidentifikasi sebagai berikut: (a.) Bentuk Sederhana; (b.) Ragam hias sebagai ciri khas ukir di Jepara (ukiran); (c.) Sistem konstruksi Knock Down, Stacking atau Modular; (d.) Penggunaan Multifungsi; (e.) Warna Natural; (f.) Bahan alami (kayu dan/atau kombinasi rotan).

Adapun desain ukir kayu yang dikembangkan meliputi dua cara produksi yaitu diproses secara manual berupa ukiran klasik, dan proses masinal dengan menggunakan mesin produksi bergaya modern yang mengembangkan stilasi ornamen tradisional.

Ujicoba luaran penelitian ini berupa prototype yaitu ukiran manual dan ukiran masinal yang diterapkan dalam furniture. Implementasi ujicoba tersebut berupa prototype terwujud sebagai berikut:

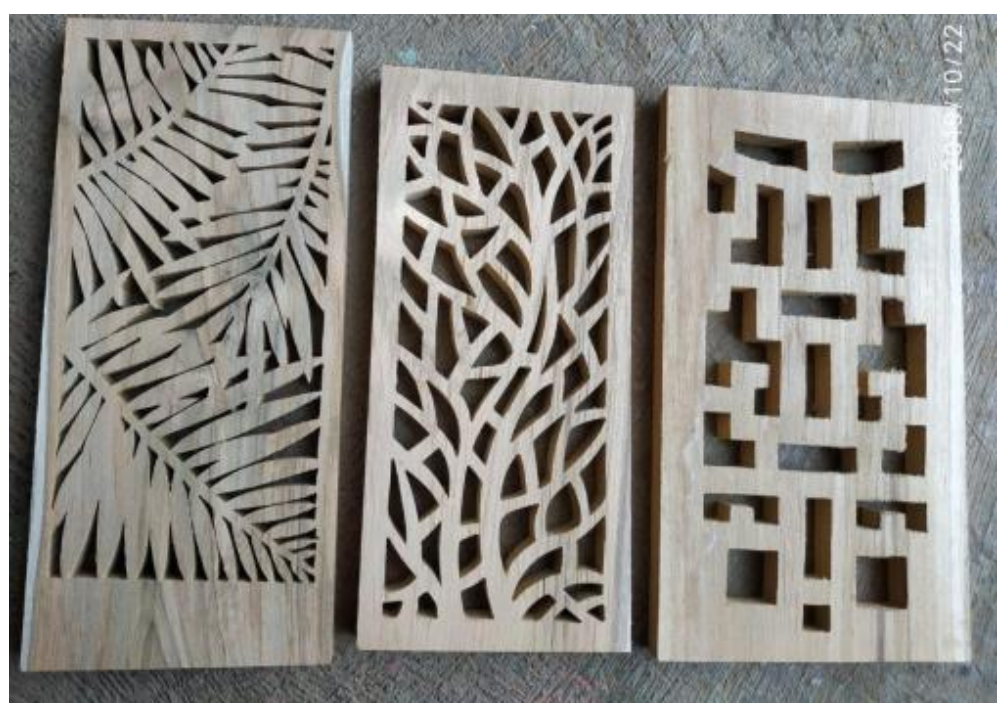

Gambar 1. Stilasi ornamen ukiran bergaya oriental untuk sandaran kursi rotan dengan konstruksi knockdown system dengan proses masinal (CNC Router).

(Desain: Eddy Supriyatna, 2019) 


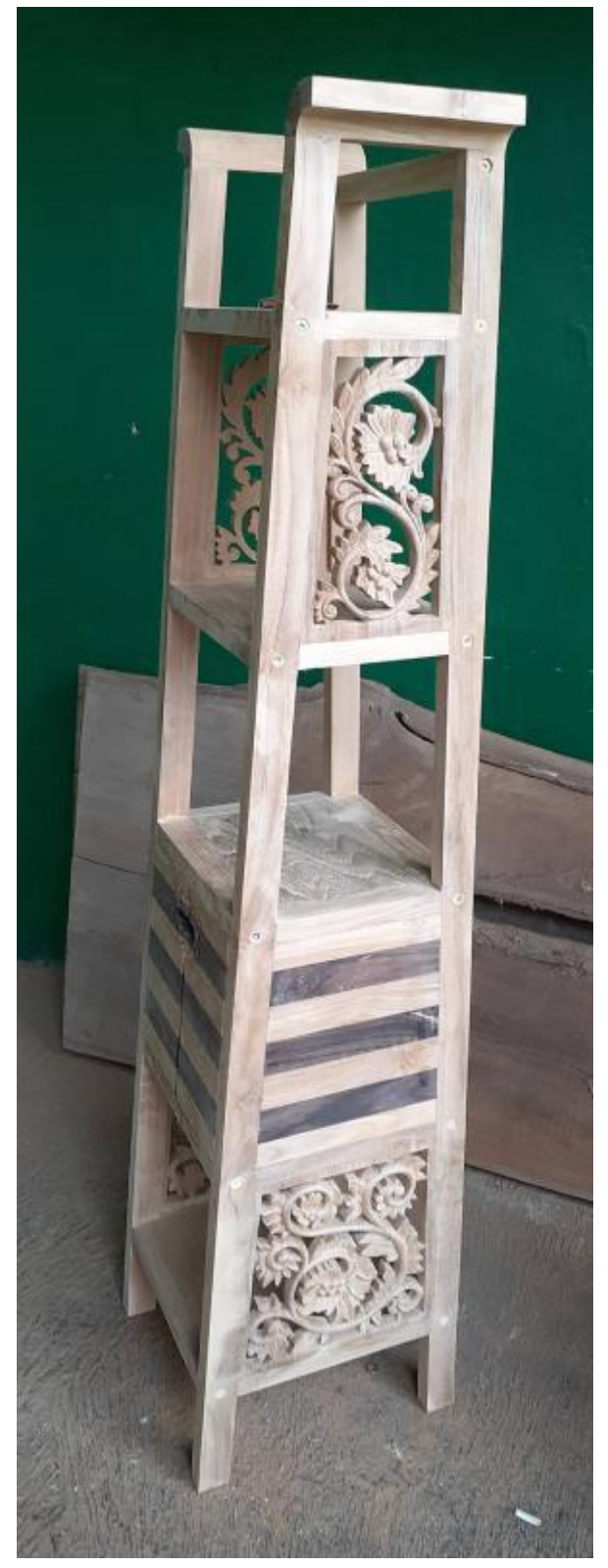

Gambar 2.Ornamen ukiran multirack dengan proses manual dan furniture diproses secara masinal dengan knockdown system. (Desain: Eddy Supriyatna, 2019) 


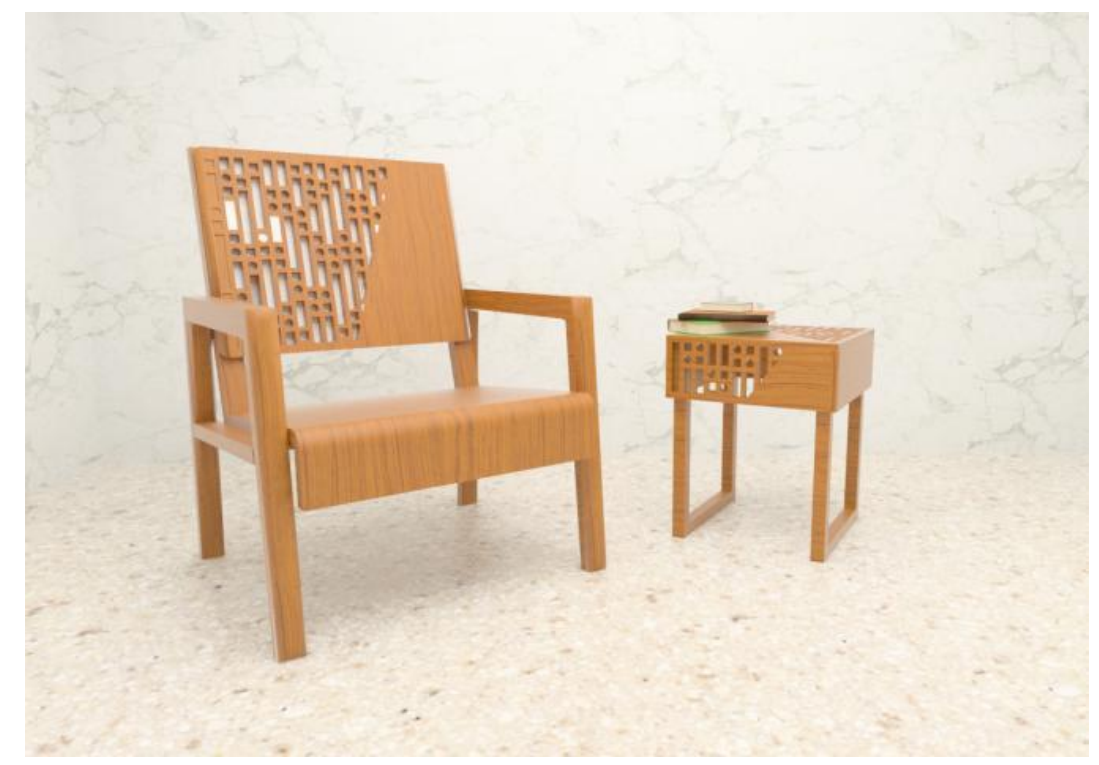

Gambar 3. Furniture dan stilasi ornamen batik, diproses secara masinal (CNC Router) dan menggunakan konstruksi knockdown system. (Desain: Maitri Widya Mutiara, 2019)

\section{KESIMPULAN DAN SARAN}

Bersadarkan kondisi tersebut, maka dapat disimpulkan bahwa ornamen ukiran kayu di Jepara selayaknya menjadi unggulan furniture. Sebab, ukiran sebagai local genius Jepara dapat digunakan sebagai perangkat daya saing ekspor dan perangkat nilai tambah ekonomi. Potensi para pengukir pun dapat berkembang secara kontinyu dan tidak punah oleh situasi zaman yang kian canggih. Desain ukiran Jepara dapat dikembangan dengan stilasi berbasis perkawinan berbagai budaya sesuai dengan sasaran ekspor yang akan dituju. Desain memegang peranan potensial dalam pengembangan industri furniture ukir kayu di Jepara.

Perpaduan proses manual dan masinal dalam proses produksi furniture menjadi nilai tambah di dalam pengembangan desain di Jepara. Oleh karena itu, disarankan agar para desainer dan pelaku industri furniture di Jepara dapat memberdayakan potensi ukir kayu dengan beragam ornamennya di dalam mengembangkan desain furniture di Jepara, khususnya untuk furniture yang menggunakan sistem konstruksi knockdown, sehingga lebih efisien di dalam pengiriman produknya.

\section{Ucapan Terima Kasih (Acknowledgement)}

Terima kasih kami sampaikan kepada Rektor Universitas Islam Nahdlatul Ulama di Jepara yang sepakat bekerjasama dengan Rektor UNTAR di Jakarta. Para peserta FGD di Jepara yaitu para dosen desain di Unisnu, Ketua KADIN Jepara, Ketua DPD HIKMI Jepara, Anggota DPRD Jepara dan DPRD Jawa Tengah, para pelaku industri furniture di Jepara. Terima kasih juga pada tim workshop UNISNU, pemilik industri Kharisma Jati, dan Idea furniture yang telah bersedia membuat prototype. Terima kasih pada pakar pemasaran furniture, Bapak Tenggono Chuandra Phoa, pakar furniture Jepara, Prof. S.P. Gustami, dan pakar ukir kayu, Sukarno, Ketua Umum DPP ASMINDO, Ketua ASMINDO Komda Jepara, serta Satori Rattan di Cirebon. Selain itu terima kasih pada Rektor UNTAR, Direktur LPPM, dan Kemenristekdikti RI. 


\section{REFERENSI}

Amir, M.S. (2000). Strategi Pemasaran Ekspor. Jakarta: PT Pustaka Binaman Pressindo. Aronson, J. (1965). The Encyclopedia of Furniture. New York: Crown Publishers, Inc.,

Bennington, R. L.(2004). Second Edition. Furniture Marketing: From Product Development to Distributor. Publish: Fairchild Publication, Inc.

Boyce, C. (1985)..Dictionary of Furniture. New York: Roundtable Press Inc.

Charlotte \& Peter, F.. (2001). Modern Furniture Classics. London: Thames and Hudson.

(2012). Chairs: 1000 Masterpieces of Modern Design, 1800 to the Present Day. London: Thames and Hudson

Fremdkoper (2007). Modern Furniture (!50 Years of Design). Postdam: H.f. Fullmann.

Grs., "Demi Keuntungan Desain Jadi Korban," dalam berita Radar Kudus, 24 Juni 2005.

Gustami, S.P. (Desember 1997).’Tokoh Wanita di Balik Perkembangan Industri Seni Kerajinan Mebel Ukir Jepara," dalam Jurnal Seni,

. (2000). Seni Kerajinan Mebel Ukir Jepara: Kajian Estetik melalui Pendekatan Multidisiplin. Yogyakarta: Penerbit Kanisius,

."Industri Seni Kerajinan Mebel Ukir Jepara: Kontinuitas dan Perubahannnya,"paper disajikan dalam rangka Membangun City Branding Jepara The World Carving Centre di Jepara, 17 Desember 2008.

Gitosudarmo, I. (1982). Sistem Perencanaan dan Pengendalian Produksi.Yogyakarta: Fakultas Ekonomi Universitas Gadjahmada.

Gummesson, E. (1991). Qualitative Methods in Management Research. London: Sage Publications.

Herwig, O. (2008). Universal Design. Basel: Switzerland Part of Springer Science + Bussiness media.

Heskett, J. (1980). Desain Industri. Terj. Chandra Johan. Jakarta: CV. Rajawali.

Hollensen, Svend. (2014). Sixth edition. Global Marketing. First Publish 1998 by Prentice Hall (print). Publish: Prentice Hall

Irawan, H. (2002). 10 Prinsip Kepuasan Pelanggan. Jakarta: PT. Elex Media Komputindo.

Johansson, J. K. (2009). Global Marketing: Foreign Entry, Local Marketing, and Global Management. Publisher: Paul Ducham.

Kar-59. (2005). "Desain Mebel Jepara Didikte Konsumen," dalam berita Suara Merdeka, 22 Juni

Peter, J. P.\&. Olson, J.C. (1999). Consumer Behavior: Perilaku Konsumen dan Strategi Pemasaran.Terj. Damos Sihombing. Jakarta: Penerbit Erlangga.

Pink, D. H. (2007). Misteri Otak Kanan Manusia. Terj. Rusli. Jogjakarta: Think Jogjakarta.

Sup, (25 Juni 2005). "Desain Dapat Menjadi Pintu Gerbang Perubahan," dalam berita Kompas, Edisi Jawa Tengah, hal. H.

Marizar, E.S (2003). Mebel Klasik: Paradigma Desain di Eropa. Tangerang, Gamma Pustaka, 2003. . (2007).Kursi Klasik. Jakarta: PT. Prima Infosarana Media,

. (2013). Kursi Kekuasaan Jawa. Yogyakarta: Narasi.

(2015)."Trend Desain Furniture di Era Pasar Global (Studi Kasus: The 20th Shanghai International Furniture Show 2014 di China."Furnicraftoday.Jakarta: Asosiasi Mebel dan Kerajinan Nasional. Edisi Maret, hal. 24-27.

. (2005). Designing Furniture: Teknik Merancang Mebel Kreatif.

Yogyakarta: Media Pressindo.

Stem, S. (1989). Designing Furniture from Concept to Shop Drawing: a Practical Guide. Newtown: The Taunton Press.

Wijaya, F. (1996). Pemasaran 2000. Yogyakarta: BPFE.

Yates, S. (1988). An Encyclopedia of Chairs. London: Quintet Publishing Limited, 